\title{
Incidence \& Risk Factors Associated with Carotid Disease in Patients Undergoing Coronary Artery Bypass Grafting Surgery
}

\author{
Hamoud Obied*, Asim Miari, Mohammed Alreshidan, Fahad Alghofaili, \\ Mohammad Ibrahim, Abdulaziz Albaradai, Mohammed Koudieh
}

Cardiac Surgery Department, Prince Salman Heart Center, Riyadh, KSA

Email: ${ }^{*}$ obeidha@yahoo.com

Received 8 January 2014; revised 8 February 2014; accepted 15 February 2014

Copyright (C) 2014 by authors and Scientific Research Publishing Inc.

This work is licensed under the Creative Commons Attribution International License (CC BY). http://creativecommons.org/licenses/by/4.0/

cc) (i) Open Access

\section{Abstract}

Objective: The purpose of this study was to evaluate the true incidence and the risk factors associated with carotid disease in the sitting of high risk patients undergoing coronary artery bypass graft (CABG) using carotid duplex scan and to find out if routine preoperative carotid duplex scan is needed among all these patients. Methods: This retrospective study included 402 consecutive patients who underwent bilateral carotid duplex scan admitted for CABG during the period from January 2006 to December 2008. We excluded patients in cardiogenic shock who were taken to operating room emergently. Results: The prevalence of associated risk factors showed diabetes mellitus recorded the highest (93.3\%) whereas peripheral vascular disease the lowest $(1.7 \%)$, hypertension (89.3\%), dyslipidemia $(72.6 \%)$, smoker $(21.1 \%)$, left main disease $(4.7 \%)$, and previous stroke (3\%). Patients undergoing CABG has high incidence of carotid disease $(68.7 \%)$ and severe stenosis is more in patients aged 60 and above $(13.5 \%)$ versus $(2.3 \%)$ in age $<60$. There is a high risk group for severe carotid stenosis (age $>60$, previous stroke and left main disease). Conclusion: This study showed that carotid screening is recommended for all patients who are undergoing CABG due to high incidence of carotid disease.

\section{Keywords}

Carotid Artery Disease, Coronary Artery Bypass Grafting, Incidence, Risk Factors, Carotid Duplex Scan

\section{Introduction}

Significant carotid artery stenosis (CAS) is an important incremental risk factor for the development of periop-

*Corresponding author.

How to cite this paper: Obied, H., et al. (2014) Incidence \& Risk Factors Associated with Carotid Disease in Patients Undergoing Coronary Artery Bypass Grafting Surgery. Open Journal of Thoracic Surgery, 4, 17-20.

http://dx.doi.org/10.4236/ojts.2014.42005 
erative neurologic injury following coronary artery bypass grafting (CABG) [1]. Association of carotid disease with coronary artery disease has been confirmed in previous studies, but the true incidence in different patients population, especially in patients with high incidence of risk factors was not addressed in details. Carotid sonographic screening (duplex and color Doppler sonography) is readily performed before elective bypass surgery at many institutions to identify such patients, although the clinical approach taken after their identification remains in contention (initial endarterectomy, combined endarterectomy and bypass, close postbypass monitoring with later endarterectomy) [2].

\section{Methods and Materials}

The study was a retrospective single institutional analysis between January 2006 and December 2008, 402 consecutive patients undergoing CABG surgery underwent bilateral Doppler carotid sonography examination preoperatively. Patients in cardiogenic shock who were taken to operating room emergently were excluded from this study. All patients were examined by duplex and color Doppler imaging of the common, internal, external carotid and vertebral arteries (CCA, ICA, ECA, and VA respectively) for any lesion with or without stenosis. The degree of stenosis was expressed as the percentage of luminal narrowing.

We studied the following risk factors; diabetes mellitus (DM), hypertension (HTN), smoking, stroke, left main stem coronary artery disease, peripheral vascular disease (PVD), dyslipidemia (DLP), and aortic valve stenosis (AS) in association with coronaty artery disease. Statistical analysis performed using SPSS version 17. Multivariate regression and correlation statistical test were applied.

\section{Results}

Of 402 patients constituted our population during the period of the study, there were 304 males (76\%) and 98 females (24\%). Table 1 showed the frequency of patients by age. The majority of patients were below age of 65 . Table 2 lists the risk factors in association with carotid disease. People who are aged 65 and above and dyslipidemia are significantly associated with carotid stenos is (P-value $<0.0001$ ). We found carotid artery disease in 276 (69\%) of patients population which range from atherosclerotic changes without stenosis to severe $>75 \%$ stenosis (Table 3 ).

\section{Discussion}

Association of carotid disease with coronary artery disease has been confirmed in previous studies [3]-[8], but the true incidence in different patient population, especially in patients with high incidence of risk factors was not addressed in details. To date, no selection criteria have been definitively proposed to identify patients for carotid sonographic screening before elective CABGS [2] and some authors concluded that the risk of postoperative stroke in a patient with no history of any form of cerebral ischemia is low [4] [5] [8]-[11] but in our study we found it worth to screen all patients undergoing CABG surgery.

In this study we found the prevalence of carotid disease is high (69\%) and significant stenosis is $24 \%$ in patient undergoing CABG surgery which increase the risk of neurological injury [1]. This is consistent with previous studies which have reported a prevalence of $1.7 \%-22 \%$ in CABG patients depending on definitions of "significant" stenosis, methods of screening, and population demographics [8] [12] [13]. D'Agostino et al. [4] and Durand et al. [8] identified an age $>65$ years, PVD, prior CVA, left main coronary disease of $>50 \%$, female

\begin{tabular}{|c|c|c|}
\hline Age & No. (\%) & $P$ value \\
\hline$\geq 65$ & 160 (40\%) & $<0.0001$ \\
\hline$<65$ & $242(60 \%)$ & \\
\hline$\leq 45$ & 29 (7\%) & \\
\hline $46-55$ & 95 (24\%) & \\
\hline $56-64$ & 118 (29\%) & \\
\hline
\end{tabular}


Table 2. Risk factors associated with carotid artery disease.

\begin{tabular}{ccc}
\hline Risk factors & $\%$ & P Value \\
\hline DM & 93.3 & NS \\
HTN & 89.3 & \\
DLP & 72.6 & $<0.0001$ \\
Smoking & 21.1 & \\
LMS & 4.7 & \\
TIA/CVA & 3 & \\
Calcified Aorta & 2.2 & \\
PVD & 1.7 & \\
AS & 1.7 & \\
\hline
\end{tabular}

DM: Diabetes mellitus; HTN: Hypertension; DLP: Dyslipidemia; LMS: Left main stem disease; TIA: Transient ischemic attack; CVA: Cerebrovascular accident; PVD: Peripheral vascular disease; AS: Aortic stenosis.

Table 3. Incidence of carotid artery disease in patients underwent CABG surgery.

\begin{tabular}{cc} 
Carotid artery disease & No (\%) \\
Normal & $126(31 \%)$ \\
Mild $\leq 50 \%$ stenosis & $54(14 \%)$ \\
Soderate $=51 \%-74 \%$ stenosis & $24(6 \%)$ \\
Others $=$ atheromatous changes without stenosis & $16(4 \%)$ \\
\hline
\end{tabular}

gender, and hypertension as risk factors for significant carotid stenosis.

In our study, we compared the incidence of carotid disease against known risk factors, that is, DM, HTN, DLP, Smoking, LMS, TIA/CVA, calcified aorta, PVD, AS and advanced age. With the use of logistic regression analysis according to a correlation statistical test we found that increasing age and DLP are significantly associated with carotid stenosis (p-values < 0.0001). However, gender, DM, HTN, smoking, LMS, TIA/CVA, calcified aorta, PVD and AS did not show correlation with carotid stenosis. Our study agreed with the study by Siminelakis et al. [14] which revealed that, Female gender is not a predictive factor for carotid stenosis in CABG patients; however, women undergoing CABG are at greater risk for major complications than men because of the comorbid conditions that are associated with the later age at which women present for coronary surgery and not because of gender. The high incidence of multiple risk factors in our patients undergoing CABG surgery with increased incidence of carotid disease, will put them in high risk of perioperative mortality and morbidity including Stroke which is a devastating complication after cardiac surgery.

\section{Conclusion}

Preoperative diagnosis of carotid disease is very important in reducing the risk of perioperative stroke after cardiac surgery. Carotid duplex screening is a non-invasive cost effective method for preoperative screening.

\section{References}

[1] Faggioli, G.L., Curl, G.R. and Ricotta, J.J. (1990) The Role of Carotid Screening before Coronary Artery Bypass. Journal of Vascular Surgery, 12, 724. http://dx.doi.org/10.1067/mva.1990.24458

[2] Sheiman, R.G. and Janne d’Othée, B. (2007) Screening Carotid Sonography before Elective Coronary Artery Bypass Graft Surgery: Who Needs It. American Journal of Roentgenology, 188, W475-W479. 
http://dx.doi.org/10.2214/AJR.06.1024

[3] Berens, E.S., Kouchoukos, N.T., Murphy, S.F. and Wareing, T.H. (1992) Preoperative Carotid Artery Screening in Elderly Patients Undergoing Cardiac Surgery. Journal of Vascular Surgery, 15, 313-323. http://dx.doi.org/10.1016/0741-5214(92)90253-5

[4] D’Agostino, R.S., Svensson, L.G., Neumann, D.J., Balkhy, H.H., Williamson, W.A. and Shahian, D.M. (1996) Screening Carotid Sonography and Risk Factors for Stroke in Coronary Artery Surgery Patients. The Annals of Thoracic Surgery, 62, 1714-1723. http://dx.doi.org/10.1016/S0003-4975(96)00885-5

[5] Gerraty, R.P., Gates, P.C. and Doyle, J.C. (1993) Carotid Stenosis and Perioperative Stroke Risk in Symptomatic and Asymptomatic Patients Undergoing Vascular or Coronary Surgery. Stroke, 24, 1115-1118. http://dx.doi.org/10.1161/01.STR.24.8.1115

[6] Hogue, C.W., Murphy, S.F., Schechtman, K.B. and Davila Roman, V.G. (1999) Risk Factors for Early or Delayed Stroke after Cardiac Surgery. Circulation, 100, 642-647. http://dx.doi.org/10.1161/01.CIR.100.6.642

[7] Salasidis, G.C., Latter, D.A., Steinmetz, O.K., Blair, J.F. and Graham, A.M. (1995) Carotid Artery Duplex Scanning in Preoperative Assessment for Coronary Artery Revascularization: The Association between Peripheral Vascular Disease, Carotid Artery Stenosis, and Stroke. Journal of Vascular Surgery, 21, 154-162. http://dx.doi.org/10.1016/S0741-5214(95)70254-7

[8] Durand, D.J., Perler, B.A., Roseborough, G.S., Grega, M.A., Borowicz Jr., L.M., Baumgartner, W.A. and Yuh, D.D. (2004) Mandatory versus Selective Preoperative Carotid Screening: A Retrospective Analysis. The Annals of Thoracic Surgery, 78, 159-166. http://dx.doi.org/10.1016/j.athoracsur.2004.02.024

[9] Furlan, A.J. and Craciun, A.R. (1985) Risk of Stroke during Coronary Artery Bypass Graft Surgery in Patients with Internal Carotid Artery Disease Documented by Angiography. Stroke, 16, 797-799. http://dx.doi.org/10.1161/01.STR.16.5.797

[10] Brener, B.J., Brief, D.K., Alpert, J., Goldenkranz, R.J. and Parsonnet, V. (1987) The Risk of Stroke in Patients with Asymptomatic Carotid Stenosis Undergoing Cardiac Surgery: A Follow-Up Study. Journal of Vascular Surgery, 5, 269-279. http://dx.doi.org/10.1016/0741-5214(87)90135-2

[11] Ghosh, J., Murray, D., Khwaja, N., Murphy, M.O. and Walker, M.G. (2005) The Influence of Asymptomatic Significant Carotid Disease on Mortality and Morbidity in Patients Undergoing Coronary Artery Bypass Surgery. European Journal of Vascular and Endovascular Surgery, 29, 88-90. http://dx.doi.org/10.1016/j.ejvs.2004.07.011

[12] Cosgrove, D.M., Hertzer, N.R. and Loop, F.D. (1986) Surgical Management of Synchronous Carotid and Coronary Artery Disease. Journal of Vascular Surgery, 4, 690-694. http://dx.doi.org/10.1016/0741-5214(86)90310-1

[13] Schwartz, L.B., Bridgman, A.H., Kieffer, R.W., et al. (1995) Asymptomatic Carotid Artery Stenosis and Stroke in Patients Undergoing Cardiopulmonary Bypass. Journal of Vascular Surgery, 21, 146-153. http://dx.doi.org/10.1016/S0741-5214(95)70253-9

[14] Siminelakis, S., Kotsanti, A., Siafakas, M., Dimakopoulos, G., Sismanidis, S., Koutentakis, M., Paziouros, C. and Papadopoulos, G. (2009) Is There Any Difference in Carotid Stenosis between Male and Female Patients Undergoing Coronary Artery Bypass Grafting? Interactive Cardiovascular Thoracic Surgery, 9, 823-826. http://dx.doi.org/10.1510/icvts.2009.213249 